\title{
openheart Utility of conventional aortic root shot angiography for SAPIEN 3 prosthesis sizing in TAVI: feasibility and inter- reader variability
}

\author{
Laura Gansera, ${ }^{1}$ Bernhard UIm, ${ }^{2}$ Peter Bramlage (D) ${ }^{3}$ Stephan Krapf, ${ }^{1}$ \\ Frank Oertel, ${ }^{1}$ Tobias Mueller-Honold, ${ }^{1}$ Wolfgang von Scheidt, ${ }^{4}$ Christian Thilo ${ }^{1}$
}

To cite: Gansera L, Ulm B, Bramlage $P$, et al. Utility of conventional aortic root shot angiography for SAPIEN 3 prosthesis sizing in TAVI: feasibility and inter-reader variability. Open Heart 2019;6:e001201. doi:10.1136/ openhrt-2019-001201

Received 28 October 2019 Revised 10 December 2019 Accepted 12 December 2019

Check for updates

C) Author(s) (or their employer(s)) 2019. Re-use permitted under CC BY-NC. No commercial re-use. See rights and permissions. Published by BMJ.

${ }^{1}$ Department of Cardiology, Klinikum Augsburg, Herzzentrum Augsburg-Schwaben, Augsburg, Germany

${ }^{2} U S B B U$, Unabhängige statistische Beratung, Munich, Germany

${ }^{3}$ Institute for Pharmacology and Preventive Medicine, Cloppenburg, Germany ${ }^{4}$ Department of Cardiac and Thoracic Surgery, Klinikum Augsburg, Herzzentrum Augsburg-Schwaben, Augsburg, Germany

Correspondence to Dr Christian Thilo; christian. thilo@klinikum-augsburg.de

\section{ABSTRACT}

Background The gold-standard approach to prosthesis sizing before transcatheter aortic valve implantation (TAVI) is multislice computed tomography (MSCT). We aimed to investigate whether conventional aortic root angiography (CA) alone can reliably facilitate valve selection and to describe its inter-reader variability.

Methods Five TAVI specialists ( 3 interventional cardiologists and 2 cardiac surgeons) independently reviewed preprocedural CAs for 50 patients implanted with the Edwards SAPIEN 3 valve.

Results The prosthesis size selected based on visual CA appraisal matched that based on MSCT in $60 \%$ of cases (range: 50\%-68\%), with undersizing in $11 \%(4 \%-33 \%)$ and oversizing in $29 \%(10 \%-46 \% ; p=0.187$ for equality of the proportions test). Agreement between CA-based and MSCT-based valve selection was moderate $(\mathrm{K}=0.41$; $\mathrm{KW}=0.61$ ). Reassessment of choice following awareness of the annulus long-axis diameter did not significantly improve this agreement $(0.40$ and 0.63 , respectively), though more undersizing (14\%) and less oversizing (25\%) occurred. Correct valve selection was more common in interventional cardiologists than cardiac surgeons (66\% vs $53 \% ; p=0.0391$ ), who made more oversizing errors. Conclusions There is a modest agreement between CA-based and MSCT-based SAPIEN 3 selection. Although the former should not be performed routinely, it may be informative in settings where MSCT and transoesophageal echocardiography are unavailable.

\section{INTRODUCTION}

In patients with aortic stenosis undergoing transcatheter aortic valve implantation (TAVI), erroneous estimation of annulus parameters leading to over/undersizing of the transcatheter heart valve (THV) can result in serious consequences. ${ }^{1}$ These include annular rupture, ${ }^{2}$ conduction disorders, ${ }^{3}$ incomplete prosthesis expansion, prosthesis embolisation ${ }^{4}$ and a greater degree of residual paravalvular leak (PVL). ${ }^{5}{ }^{6}$ Consequently, accurate preprocedural sizing is crucial.

\section{Key questions}

What is already known?

- The gold-standard approach to prosthesis sizing before transcatheteraortic valve implantation (TAVI) is multislicecomputed tomography (MSCT). Although it is true that MSCT has improved the accuracy of long-axis and short-axis annular diameter estimations, particularly in the case of highly calcified valves, it also exposes the patient to harmful radiation and requires the use of contrast agents, limiting its application in patients with renal comorbidity.

What does this study add?

- We aimed to investigate whether conventionalaortic root angiography (CA) alone can reliably facilitate valve selection and to describe its inter-reader variability. We found only moderate agreement between the transcatheter heart valve (THV) selection made based on CA aortic root shot assessment and that made using the gold-standard MSCT approach.

How might this impact on clinical practice?

- CA-based THV selection should not be performed routinely for the purpose of valve sizing in resourcerich settings. However, it may be a reasonable approach in the case that MSCT and transoesophageal echocardiography are unavailable, particularly given that it is already a routine step in the TAVI procedure.

Until 2010, transoesophageal echocardiography (TEE) was the most commonly used imaging modality for THV size selection. However, over time it has been gradually replaced by multislice computed tomography (MSCT). ${ }^{7}$ The latter multiplanar imaging technique is now the gold standard for preprocedural assessment of aortic root anatomy, used to determine the form and dimensions of the annulus, its distance from the coronary ostia, the burden and distribution of calcified residues, and AV cuspidity. ${ }^{8}$ Although it is true that MSCT has improved the accuracy of long-axis and short-axis annular diameter 


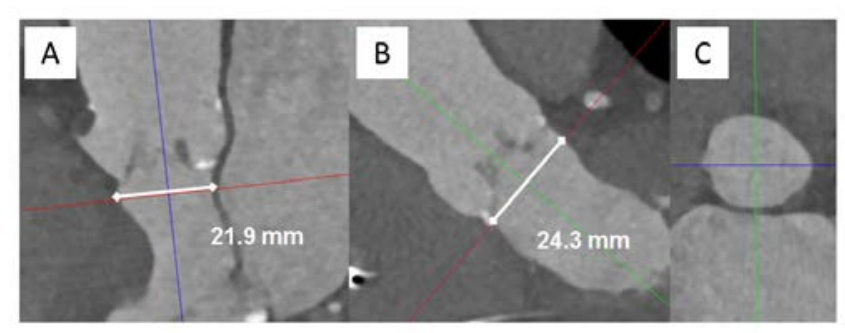

Figure 1 MSCT-based valve sizing approach. Example MSCT-based images from a 81-year-old woman with implantation of a 23-mm SAPIEN three valve. Sagittal $(A)$ and coronal (B) multiplanar reformats displaying short and long annulus diameters, respectively (mean diameter of $23.1 \mathrm{~mm}$ $[21.9+24.3 \mathrm{~mm} / 2])$. The corresponding transverse MPR is shown in (C). MSCT, multislice CT.

estimations, ${ }^{8-14}$ particularly in the case of highly calcified valves, ${ }^{15}$ it also exposes the patient to harmful radiation and requires the use of contrast agent, limiting its application in patients with renal comorbidity. ${ }^{1716}$ Furthermore, due to its high cost, MSCT may not be available in low-resource settings. For these reasons, it is useful to assess the utility of alternative imaging techniques for valve sizing in TAVI.

Conventional 2D angiography (CA) of the aortic root is routinely carried out during the TAVI procedure. ${ }^{18}$ First proposed as an aid to valve sizing in surgical aortic valve (AV) replacement by Mukharji et al, ${ }^{19}$ this well-established imaging modality is low cost and requires lower radiation and contrast agent doses compared with MSCT. To the best of our knowledge, THV selection based solely on the appraisal of a CA aortic root shot has not been compared with the gold-standard MSCT-based selection. In the present analysis, we aim to ascertain whether reliable TAVI prosthesis sizing is possible based on such CA appraisal alone and to describe the corresponding interreader variability.

\section{METHODS}

The present study was a retrospective analysis of patients who underwent TAVI at the Augsburg-Schwaben Heart centre (Augsburg Hospital, Germany) between October 2016 and March 2017. The research was approved by the local ethics committee and conducted in line with the Declaration of Helsinki. Written informed consent was unnecessary as existing anonymised data were used.

Only patients who underwent TAVI with the Edwards SAPIEN 3 THV were included in the study. The presence of a bicuspid AV or AV bioprosthesis resulted in exclusion.

Prior to TAVI, each patient underwent prospective ECG-gated MSCT with a high-pitch spiral acquisition, using a third-generation, dual-source CT scanner (Somatom Force; Siemens Healthcare, Germany). The following settings were applied: $250 \mathrm{~ms}$ gantry rotation; $66 \mathrm{~ms}$ temporal resolution; $2 \times 196 \times 0.6$ collimation; a 120 $\mathrm{kV}$ tube voltage; and a 350-500 mA tube current. Scan direction was craniocaudal, extending from above the aortic arch to below the hip. Image acquisition was optimised for the left main coronary artery at $60 \%$ of the $\mathrm{R}-\mathrm{R}$ interval. Contrast agent transit time was measured using the test bolus technique $(10 \mathrm{~mL}$ of contrast agent followed by a $50 \mathrm{~mL}$ saline flush, both administered at a flow rate of $5 \mathrm{~mL} / \mathrm{s}$ ). For MSCT angiography, $50 \mathrm{~mL}$ of contrast agent ( $350 \mathrm{mg}$ iodine $/ \mathrm{mL}$; Imeron, Bracco) were injected into an antecubital vein at a flow rate of 5 $\mathrm{mL} / \mathrm{s}$, followed by a $60 \mathrm{~mL}$ flush consisting of $80 \%$ saline and $20 \%$ contrast agent. Images were reconstructed using i26f kernel, with a slice thickness of $0.75 \mathrm{~mm}$ and an increment of $0.5 \mathrm{~mm}$.

For precise determination of the aortic annulus plane, the lowest insertion points of the right, non-coronary and left aortic cusp were aligned by stepwise manipulation of multiplanar reconstructions (figure 1). The resulting scan was used to calculate aortic annulus parameters and to determine the most appropriate THV size. MSCT image analysis was performed by a cardiologist with several years of cardiac CT experience (level 3) using Agfa Impax software.

Conventional root shot angiography (CA) using the Artis zee system (Siemens Healthcare, Germany) was also performed in each patient prior to THV implantation. This examination included an aortic root shot angiogram $\left(10^{\circ}\right.$ left anterior oblique, $10^{\circ}$ cranial view) obtained using $10 \mathrm{~mL}$ of contrast agent (Iomeprol $350 \mathrm{mg} / \mathrm{mL}$; Imeron 350, Bracco) injected into the right aortic cusp via a $5 \mathrm{~F}$ curved pigtail catheter. Precise determination of the perpendicular annulus plane was achieved according to the 'follow the right cusp' rule. ${ }^{20}$

After TAVI completion, all preprocedural CA aortic root shots were retrospectively reviewed by five experienced readers (two cardiac surgeons (R1 and R2) and three interventional cardiologists (R3-R5)). Each reader independently estimated the appropriate SAPIEN 3 valve size $(20,23,26$ or $29 \mathrm{~mm})$ based on visual CA image appraisal alone (figure 2A,C). Subsequently, the long-axis diameter of the elliptically shaped AV annulus ('annular long-axis diameter') was measured from hinge point to hinge point of the AV cusps (figure 2B,D) and each reader reassessed their selection based on this additional information.

TAVI was performed in the catheterisation laboratory by the resident Heart Team at our institution, consisting of interventional cardiologists and cardiac surgeons. In all patients, the procedure was carried out under conscious sedation with balloon aortic valvuloplasty predilation. Balloon postdilation was performed in the case of treatable residual PVL. At least one additional aortogram was acquired after prosthesis implantation.

Categorical data are presented as absolute values and proportions. Inter-reader agreement was assessed using Cohen's kappa coefficient, expressed as both unweighted kappa (K) and weighted kappa (Kw), the latter of which also considers the magnitude of the deviation. A Hotelling's T square test was used to determine the statistical significance of agreements over all raters. 

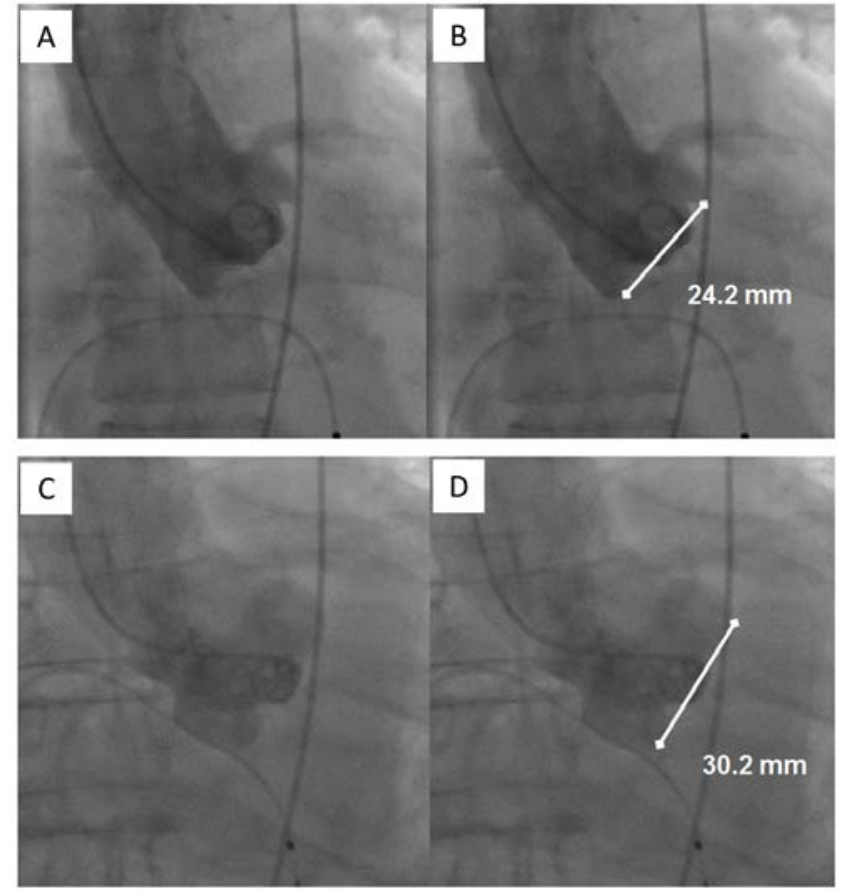

Figure 2 CA-based valve sizing approach. Example of conventional root shot angiography images for a visual appraisal ( $\mathrm{A}$ and $\mathrm{C}$ ), with subsequent measurement of the long-axis diameter of the aortic valve annulus (distance from hinge point to hinge point of the AV cusps; shown by a white arrow in (B and D). Upper panel: an 85-year-old woman with an MSCT-based mean AV diameter of $22.3 \mathrm{~mm}$ and implantation of a 23-mm SAPIEN three valve. Lower panel: an 86-year-old man with an MSCT-based mean diameter of $28.5 \mathrm{~mm}$ and implantation of a $29-\mathrm{mm}$ SAPIEN three valve. $\mathrm{AV}$, aorticvalve; $\mathrm{CA}$, conventional aortic root angiography; MSCT, multislice CT.

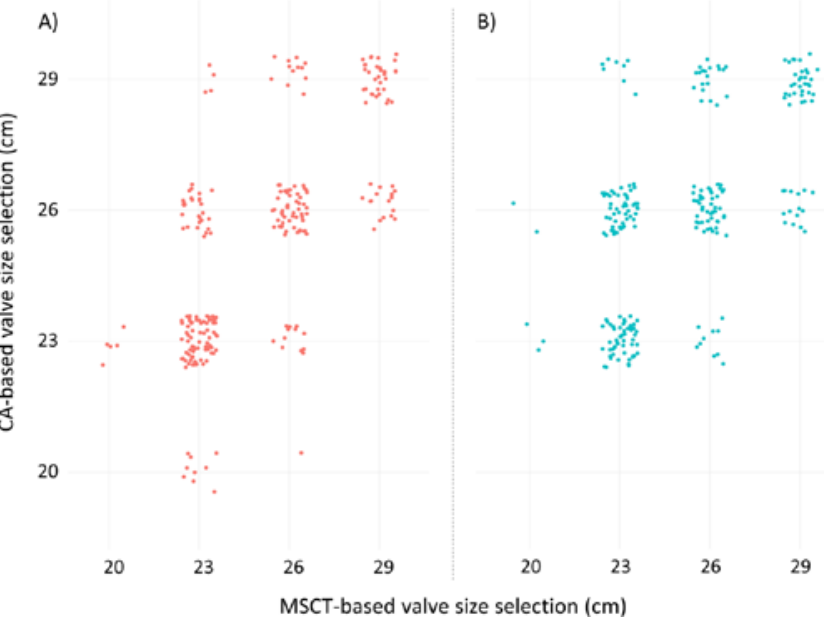

Figure 3 Agreement between CA-based and MSCT-based valve size selection when annular long-axis diameter is unknown (A) or known (B). (A) $K=0.41, K w=0.61$. (B) $K=0.40$, $\mathrm{Kw}=0.63$. $\mathrm{p}=0.951$ for the comparison between $(\mathrm{A}) \mathrm{K}$ and (B) $K ; p=0.743$ for the comparison between (A) Kw and (B) $\mathrm{Kw}$. CA, conventional aortic root angiography; K, kappa; Kw, weighted kappa; MSCT, multislice CT.
Any difference in the rate of correct valve sizing between physicians was identified using a test for equality of proportions. All statistical analyses were performed using R V.3.4.2, with a p-value of $<0.05$ considered significant.

\section{RESULTS}

In total, 50 TAVI patients met the study criteria and had both an MSCT and CA aortic root shot available for evaluation. MSCT assessment prior to TAVI resulted in the implantation of a $20-\mathrm{mm}$ valve in 1 patient $(2 \%)$, a $23-\mathrm{mm}$ valve in 23 patients (46\%), a 26-mm valve in 16 patients $(32 \%)$ and a $29-\mathrm{mm}$ valve in 10 patients $(20 \%)$.

The agreement between visual CA-based valve selection (without knowledge of the annular long-axis diameter) and MSCT-based valve selection was moderate $(\mathrm{K}=0.41$; $\mathrm{Kw}=0.61$ ) (figure 3A). On average, valve selection based on the two imaging methods matched in $60 \%$ of cases, with CA appraisal resulting in relative undersizing in $11 \%$ and oversizing in $29 \%$ of cases; however, these proportions varied substantially across individual readers (range: $50 \%-68 \%, 4 \%-22 \%$ and $10 \%-46 \%$, respectively) (figure 4A). Using the CA-based approach, R4 and R5 demonstrated the highest degree of agreement with MSCT-determined valve sizes, followed by R3, R2 and $\mathrm{R} 1$ ( $\mathrm{K}=0.52,0.51,0.42$ and 0.31 , respectively), with a test for equality of proportions resulting in a non-significant p-value of 0.37 (table 1A). In all cases, Kw was higher than $\mathrm{K}$, with the same trend seen across raters $(\mathrm{Kw}=0.73,0.73$, $0.63,0.50$ and 0.47 , respectively; $\mathrm{p}=0.15$ ). An inter-rater matrix comparison of $\mathrm{K}$ and $\mathrm{Kw}$ revealed that there were no statistically significant differences (table 2).

Overall, knowledge of the annular long-axis diameter did not result in a significantly greater agreement between CA-based and MSCT-based valve size selection $(\mathrm{K}=0.40$ vs $0.41, \mathrm{p}=0.951 ; \mathrm{Kw}=0.63$ vs $0.61, \mathrm{p}=0.753)$ (figure $3 \mathrm{~B}$ ). Accordingly, there was very little change in the rate of correct valve sizing (mean: $61 \%$ vs $60 \%$; $\mathrm{p}=0.86$ ), though more undersizing (mean: $14 \%$ vs $11 \%$; $\mathrm{p}=0.35$ ) and less oversizing (mean: $25 \%$ vs $28 \% ; \mathrm{p}=0.36$ ) occurred (figure 4B).

Awareness of the annular long-axis diameter resulted in an increase in $\mathrm{K}$ for two readers (R5: 0.52-0.56 and R1: $0.28-0.32)$ and a decrease for the other three (R4: 0.51-0.48; R3: 0.42-0.39; and R2: 0.31-0.28) (table 1). A test for equality of proportions resulted in a nonsignificant $\mathrm{p}$-value of 0.214 . Kw was again greater than $\mathrm{K}$ in all readers, being highest for $\mathrm{R} 5$, followed by $\mathrm{R} 4$, R3, R1 and R2 (0.77, 0.74, 0.62, 0.54 and 0.47 , respectively).

Overall, the proportion of correctly sized valves was higher when the CA aortic root shot was read by interventional cardiologists compared with cardiac surgeons, regardless of whether annular long-axis diameter was known $(66 \%$ vs $53 \%$; $\mathrm{p}=0.0391)$ or unknown $(66 \%$ vs $52 \%$; $\mathrm{p}=0.0177$ ) (figure 5). Both cardiac surgeons (R1 and R2) were more accurate than their interventional cardiologist counterparts (R3, R4 and R5) when visually judging the need for larger valve sizes, whereas the inverse was true 

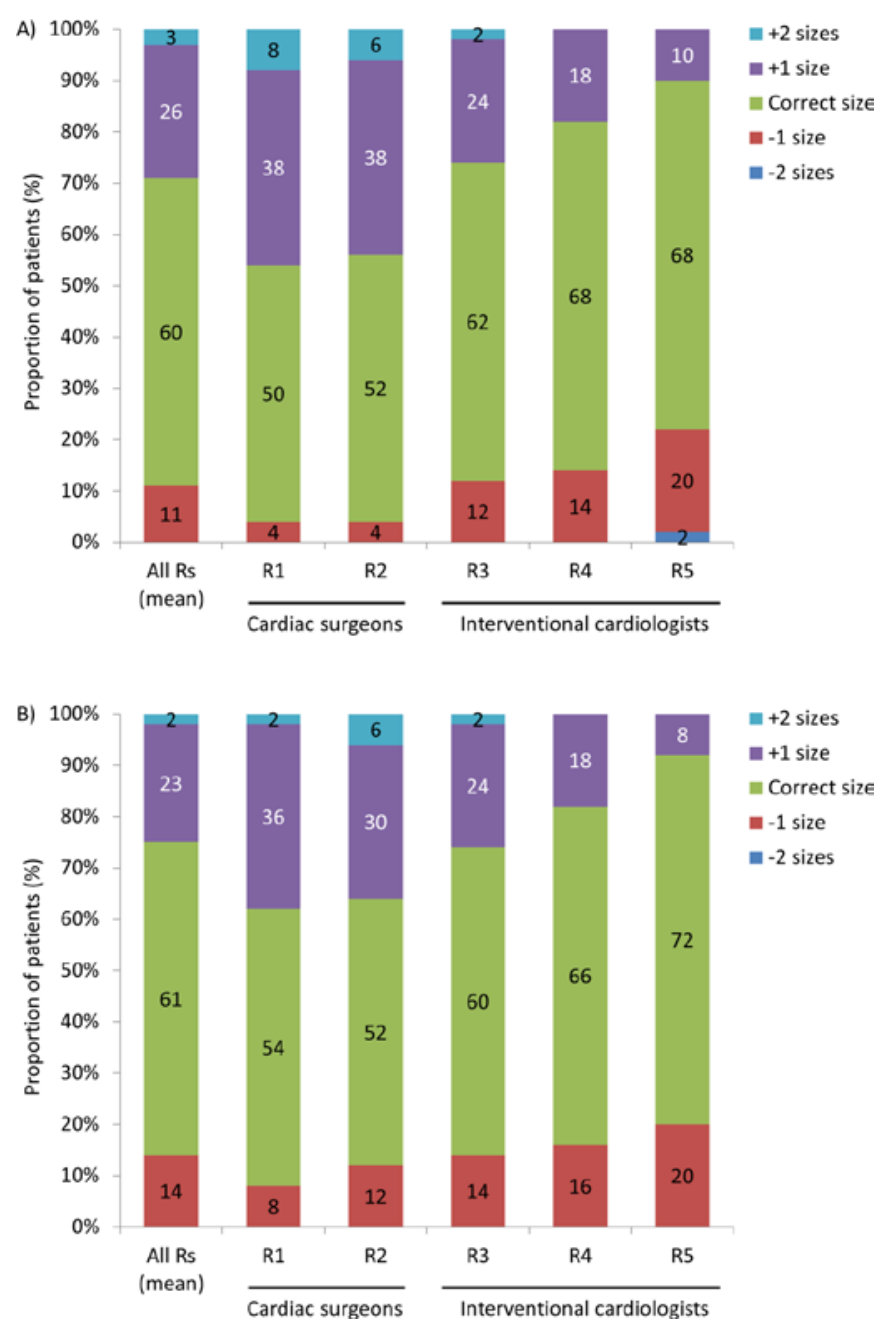

Figure 4 Proportion of correctly sized/undersized/oversized valves based on $C A$ appraisal without $(A)$ and with $(B)$ awareness of the annular long-axis diameter. 'Correct' valve size is defined as that selected based on preprocedural MSCT. CA, conventional aortic root angiography; R, reader; MSCT, multislice CT; R, reader.

for intermediate-sized valves (table 1A). Additionally, cardiac surgeons less commonly made undersizing errors based on visual CA appraisal, but more commonly made oversizing errors (figure 4A). However, these unbalances became notably less pronounced when the annular longaxis diameter was known (table 1B).

\section{DISCUSSION}

The present analysis suggests that CA aortic root shot appraisal results in only modestly accurate prosthesis sizing, as compared with the gold-standard MSCT reference size. Furthermore, CA-based quantification of the annular long-axis diameter did not improve the overall accuracy of valve size selection. As such, CA-based THV sizing should not routinely replace its MSCT-based counterpart. Inter-reader variability was modest, with the interventional cardiologists in our small study generally making more appropriate selections than the cardiac surgeons.
On average, $60 \%$ of valves were correctly sized based on the $\mathrm{CA}$ aortic root shot, with the fair-to-moderate agreement between CA-guided and MSCT-guided selections. ${ }^{21}$ Although this does not seem to be particularly promising at first glance, it is also important to consider the degree of inaccuracy, with severe over/undersizing resulting in a greater likelihood of complications. ${ }^{22}$ When the magnitude of each discrepancy was taken into account by $\mathrm{K}$ weighting, the moderate-to-substantial agreement was achieved, ${ }^{21}$ suggesting that inaccuracies were largely small. This is further demonstrated by the fact that only $3 \%$ of CA-guided valve selections were $\geq 1$ size away from their MSCT-guided counterparts. Furthermore, the majority of inaccuracies led to oversizing rather than undersizing errors. This is significant given that moderate oversizing (5\%-15\% for the SAPIEN 3) has been shown to be protective against postprocedural PVL, ${ }^{23}$ whereas undersizing has no clinical utility and results in incomplete apposition to the native aortic annulus. ${ }^{24}$ In addition, several common oversizing-related complications, such as conduction abnormalities, do not necessarily translate into poorer outcomes, ${ }^{25}{ }^{26}$ whereas PVL, the most common undersizing-related complication, has been highlighted as an independent risk factor for postprocedural mortality. ${ }^{24}$ Nevertheless, the advantage of slight oversizing was likely already accounted for in MSCT-based valve selection, meaning that the oversizing observed with CA-based valve selection would be more severe than it first appears. This is concerning, given that severe oversizing of balloon-expandable valves has been associated with a higher risk of aortic root rupture, ${ }^{2}$ a rare $(0.5 \%-1 \%)$ but often fatal TAVI complication. ${ }^{27}$

Although the above-mentioned findings suggest that CA-based THV sizing is not an appropriate substitute for the MSCT gold standard in routine clinical practise, they demonstrate it to provide a reasonable approximation of size requirements, with only a small, non-significant degree of inter-rater variation. As such, it may be useful to guide valve selection in low-resource settings where access to MSCT or TEE technology is limited. Furthermore, given that only a fraction of the contrast agent used for MSCT was required for CA, the latter approach may be an interesting alternative for patients at high risk of contrast-induced nephropathy. ${ }^{28}$ As always, a balance must be struck between the risks and benefits of each technique.

In general, knowledge of the annular long-axis diameter did not result in a significantly greater agreement between CA-based and MSCT-based valve size selection. Accordingly, there was very little change in the rate of correct valve sizing, though a general trend towards more undersizing and less oversizing emerged. This effect is likely related to the elliptical conformation of the AV annulus. Although MSCT allows calculation of a mean annulus diameter based on measurements of both the short and long axes, with motion-induced artefacts circumvented through gated imaging, ${ }^{29}$ 2D CA provides data only for the annular long-axis, which must then 
Table 1 Number of correct reader assessments when the annular long-axis diameter is unknown $(A)$ and known $(B)$

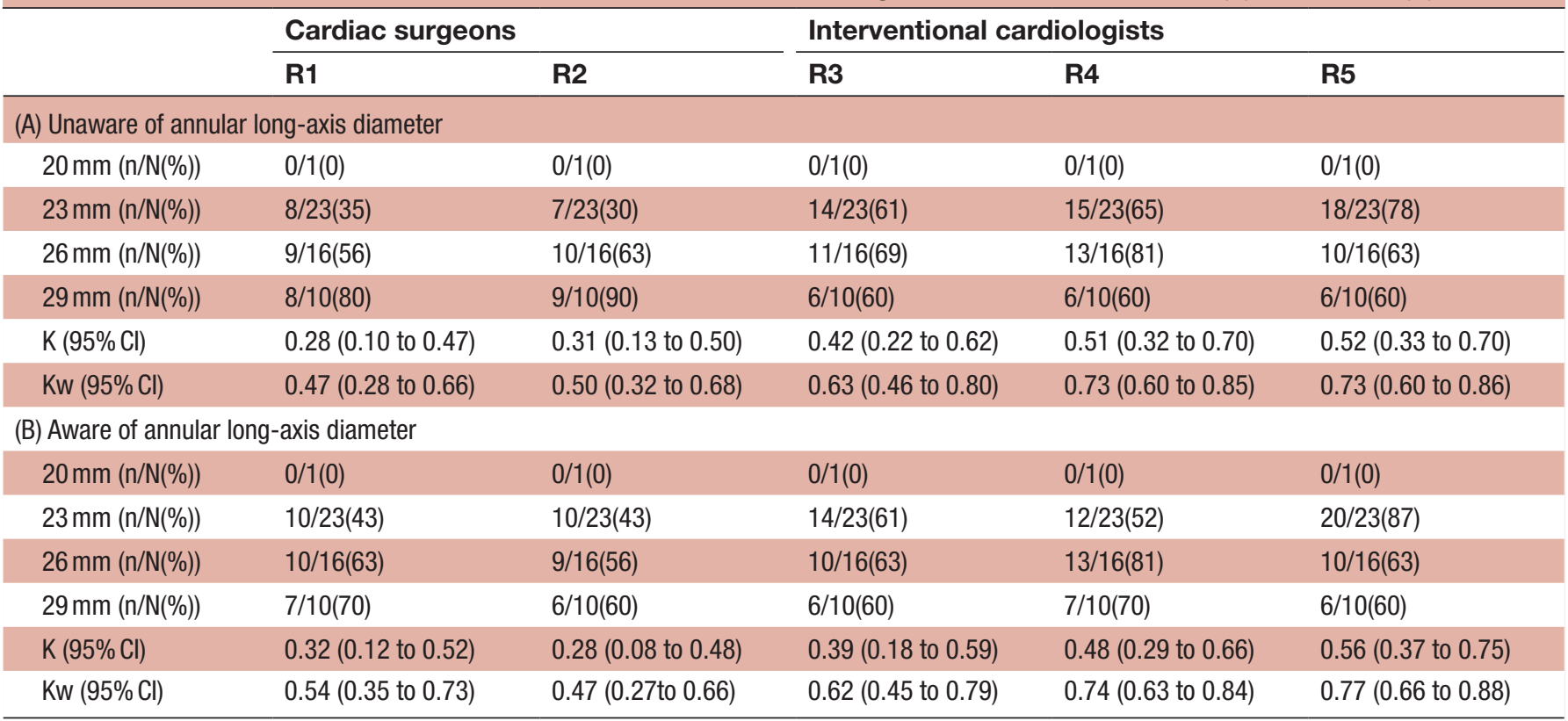

K, kappa; Kw, weighted kappa.

be used to approximate the overall annulus diameter, with no compensation for movement. The present data suggest that, on receipt of the long-axis measurements, physicians may tend towards underestimation of the shortaxis diameter and selected a smaller THV to compensate. Had this approach been used for valve selection in real life, the result would likely have been greater PVL, poorer transvalvular gradients and less scope for functional improvement. ${ }^{56}$ Physician perception seems also to play a role, with the accuracy of two readers improving and that of three readers declining when long-axis data were made available; however, these changes were small. Thus, it may be concluded that the measurement of the aortic annulus long-axis diameter provides a little-to-no clinical advantage in CA-based THV sizing and would prolong interventional times.

Overall, the proportion of correctly sized valves was higher when the CA was read by interventional cardiologists than by cardiac surgeons, regardless of whether the annular long-axis diameter was known or unknown. This highlights the importance of exploiting the particular expertise and specialty of certain Heart Team members in TAVI, with interventional cardiologists typically having more experience in the appraisal of angiography images. ${ }^{30}$ Indeed, cardiac surgeons often play a more supportive role in contemporary TAVI at well-established institutions, stepping in the case of procedural complications. ${ }^{31}$ However, based on visual CA appraisal alone, both cardiac surgeons in the present study were more accurate than their interventional cardiologist counterparts in judging the need for larger valve sizes, less frequently making undersizing errors. In contrast, oversizing errors were less commonly made by interventional cardiologists. This highlights the value of the guideline-recommended multidisciplinary Heart Team in $\mathrm{TAVI}^{8}$; indeed, it would be interesting to explore whether a collaborative effort towards CA-based valve sizing involving multiple members of the Heart Team would improve the accuracy of valve selection.

Table 2 K comparison using z-test*

\begin{tabular}{|c|c|c|c|c|c|c|}
\hline & & \multicolumn{2}{|c|}{ Cardiac surgeons } & \multicolumn{3}{|c|}{ Interventional cardiologists } \\
\hline & & R1 & $\mathbf{R 2}$ & R3 & R4 & R5 \\
\hline \multirow[t]{2}{*}{ Cardiac surgeons } & $\mathrm{R} 1$ & - & $0.825 \ddagger$ & $0.313 \ddagger$ & $0.093 \ddagger$ & $0.078 \neq$ \\
\hline & $\mathrm{R} 2$ & $0.831 \dagger$ & - & $0.425 \ddagger$ & $0.143 \ddagger$ & $0.123 \ddagger$ \\
\hline \multirow[t]{3}{*}{ Interventional cardiologists } & R3 & $0.243 \dagger$ & $0.336 \dagger$ & - & $0.531 \ddagger$ & $0.491 \ddagger$ \\
\hline & R4 & $0.061 \dagger$ & $0.096 \dagger$ & $0.510 \dagger$ & - & $0.960 \ddagger$ \\
\hline & R5 & $0.053 \dagger$ & $0.086 \dagger$ & $0.489 \dagger$ & $0.984 \dagger$ & - \\
\hline
\end{tabular}

${ }^{\star}$ For valve selection based on CA aortic root shot appraisal without knowledge of the annular long-axis diameter.

†Weighed kappa; $p$-values based on z-test.

fUnweighted kappa.

$\mathrm{CA}$, conventional root shot angiography; K, kappa. 


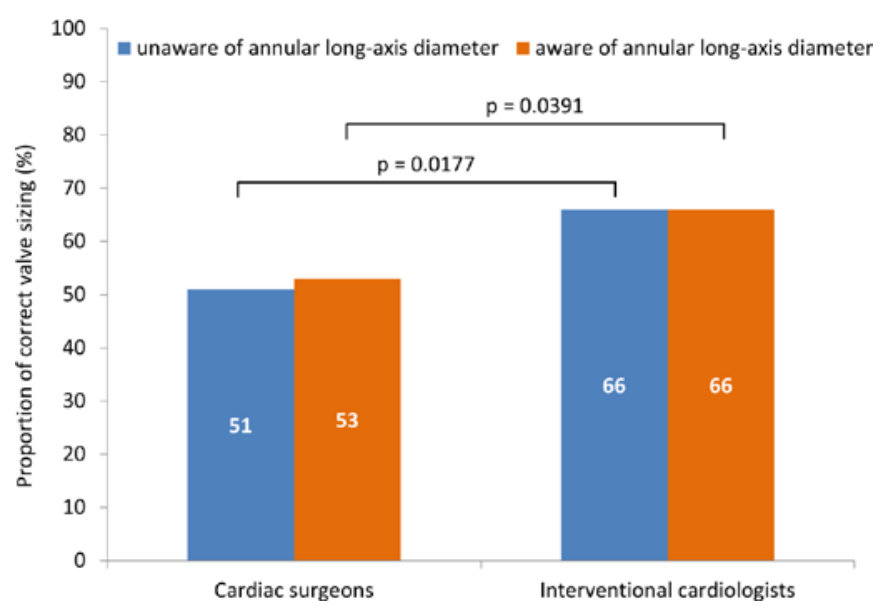

Figure 5 Comparison of the accuracy of CA-based valve selection between cardiac surgeons and interventional cardiologists with and without awareness of the annular longaxis diameter. CA, conventional aortic root angiography.

The principal limitation of the present study was the small number of readers included, becoming even more relevant when comparing the different types of cardiac specialists. Larger-scale studies would be informative. Furthermore, all readers are current practitioners at the same TAVI-proficient site, meaning that the agreement between them may be higher due to the workplace and geographical influences. As such, the present findings cannot be generalised to other institutions and cardiologists with different levels of TAVI experience. The use of one model of THV, the balloon-expandable SAPIEN 3 , also limits the generalisation of results to patients undergoing TAVI with other valve types, particularly self-expanding prostheses. Finally, the assumption that CA-based valve selection was accurate when it matched that indicated by MSCT-based sizing may be misplaced, given that sizing errors are still possible even when using the gold-standard approach. Unfortunately, data on realworld valve undersizing/oversizing at implantation were not available to corroborate MSCT-based selection in the present study.

\section{CONCLUSIONS}

There is an only moderate agreement between the THV selection made based on CA aortic root shot assessment and that made using the gold-standard MSCT approach. As such, CA should not be routinely used for the purpose of valve sizing in resource-rich settings. Nevertheless, it may be a reasonable approach in the case that MSCT or TEE is unavailable, particularly given that it is already a routine step in the TAVI procedure. In the case that the CA-based approach is used, the judgement of an interventional cardiologist may be particularly useful for maximising accuracy, whereas the supplementary view of a cardiac surgeon may help to minimise undersizing. However, any time CA-based valve selection is used, balloon sizing prior to implantation is mandatory to further improve accuracy. Further studies in a larger sample and range of readers would be informative.

Contributors $\mathrm{LG}$ and $\mathrm{CT}$ : contributed to conception and design of this work. LG, SK, FO, TM-H, WvS and CT: collected the data. BU: designed the statistical approach, analysis and interpretation. PB: outlined the first version of the manuscript, which all other authors revised for important intellectual content. All authors approved the final version of the manuscript to be submitted.

Funding Edwards Lifesciences provided funding for the preparation of this manuscript.

Disclaimer The funder had no role in the design of the study, the data collection, analysis, interpretation of data and the writing / revision of the manuscript.

Competing interests SK is a consultant for Jena Valve and Edwards Lifesciences. CT is a consultant for Boston Scientific and receives research support from Edwards Lifesciences and Boston Scientific. PB is a consultant for Abbott, Boston Scientific and Edwards Lifesciences.

Patient consent for publication Not required.

Ethics approval The research was approved by the Augsburg University ethics committee and conducted in line with the declaration of Helsinki. Written informed consent was unnecessary as existing anonymised data were utilised.

Provenance and peer review Not commissioned; externally peer reviewed.

Data availability statement Data are available upon request.

Open access This is an open access article distributed in accordance with the Creative Commons Attribution Non Commercial (CC BY-NC 4.0) license, which permits others to distribute, remix, adapt, build upon this work non-commercially, and license their derivative works on different terms, provided the original work is properly cited, appropriate credit is given, any changes made indicated, and the use is non-commercial. See: http://creativecommons.org/licenses/by-nc/4.0/.

ORCID iD

Peter Bramlage http://orcid.org/0000-0003-4970-2110

\section{REFERENCES}

1 Husser O, Rauch S, Endemann DH, et al. Impact of threedimensional transesophageal echocardiography on prosthesis sizing for transcatheter aortic valve implantation. Catheter Cardiovasc Interv 2012;80:956-63.

2 Blanke P, Reinöhl J, Schlensak C, et al. Prosthesis oversizing in balloon-expandable transcatheter aortic valve implantation is associated with contained rupture of the aortic root. Circ Cardiovasc Interv 2012;5:540-8.

3 Husser O, Pellegrini C, Kessler T, et al. Predictors of permanent pacemaker implantations and new-onset conduction abnormalities with the SAPIEN 3 Balloon-Expandable transcatheter heart valve. JACC Cardiovasc Interv 2016;9:244-54.

4 Mylotte D, Andalib A, Thériault-Lauzier P, et al. Transcatheter heart valve failure: a systematic review. Eur Heart J 2015;36:1306-27.

5 Liao Y-B, Li Y-J, Jun-Li L, et al. Incidence, predictors and outcome of Prosthesis-Patient mismatch after transcatheter aortic valve replacement: a systematic review and meta-analysis. Sci Rep 2017;7:15014.

6 Takagi H, Umemoto T, ALICE (All-Literature Investigation of Cardiovascular Evidence) Group. Prosthesis-Patient mismatch after transcatheter aortic valve implantation. Ann Thorac Surg 2016;101:872-80.

7 Delgado V, Ng ACT, van de Veire NR, et al. Transcatheter aortic valve implantation: role of multi-detector row computed tomography to evaluate prosthesis positioning and deployment in relation to valve function. Eur Heart J 2010;31:1114-23.

8 Baumgartner H, Falk V, Bax JJ, et al. 2017 ESC/EACTS guidelines for the management of valvular heart disease. Eur Heart $J$ 2017;38:2739-91.

9 Jilaihawi $\mathrm{H}$, Kashif M, Fontana G, et al. Cross-Sectional computed tomographic assessment improves accuracy of aortic annular sizing for transcatheter aortic valve replacement and reduces the incidence of paravalvular aortic regurgitation. J Am Coll Cardiol 2012;59:1275-86.

10 Vaquerizo B, Spaziano M, Alali J, et al. Three-Dimensional echocardiography vs. computed tomography for transcatheter aortic valve replacement sizing. Eur Heart $J$ Cardiovasc Imaging 2016;17:15-23. 
11 Husser O, Holzamer A, Resch M, et al. Prosthesis sizing for transcatheter aortic valve implantation--comparison of three dimensional transesophageal echocardiography with multislice computed tomography. Int J Cardiol 2013;168:3431-8.

12 Litmanovich DE, Ghersin E, Burke DA, et al. Imaging in transcatheter aortic valve replacement (TAVR): role of the radiologist. Insights Imaging 2014;5:123-45

13 Kempfert J, Van Linden A, Lehmkuhl L, et al. Aortic annulus sizing: echocardiographic versus computed tomography derived measurements in comparison with direct surgical sizing. Eur $J$ Cardiothorac Surg 2012;42:627-33.

14 Pontone G, Andreini D, Bartorelli AL, et al. Aortic annulus area assessment by multidetector computed tomography for predicting paravalvular regurgitation in patients undergoing balloon-expandable transcatheter aortic valve implantation: a comparison with transthoracic and transesophageal echocardiography. Am Heart J 2012;164:576-84.

15 Podlesnikar T, Prihadi EA, van Rosendael PJ, et al. Influence of the quantity of aortic valve calcium on the agreement between automated 3-dimensional transesophageal echocardiography and multidetector row computed tomography for aortic annulus sizing. Am J Cardiol 2018;121:86-93.

16 Sherif MA, Ince $\mathrm{H}$, Maniuc $\mathrm{O}$, et al. Two-Dimensional transesophageal echocardiography for aortic annular sizing in patients undergoing transcatheter aortic valve implantation. BMC Cardiovasc Disord 2015;15:181.

17 Wang H, Hanna JM, Ganapathi A, et al. Comparison of aortic annulus size by transesophageal echocardiography and computed tomography angiography with direct surgical measurement. Am J Cardiol 2015;115:1568-73.

18 Lasala JM, Rogers JH. Interventional procedures for adult structural heart disease. Philadelphia. PA: Elsevier Health Sciences, 2013.

19 Mukharji J, Sloan TJ, Estrera AS, et al. Measurement of aortic root size by biplane angiography before cardiac valve replacement. $A m \mathrm{~J}$ Cardiol 1984;53:1084-6.
20 Kasel AM, Cassese S, Leber AW, et al. Fluoroscopy-guided aortic root imaging for TAVR: "follow the right cusp" rule. JACC Cardiovasc Imaging 2013;6:274-5.

$21 \mathrm{McHugh}$ ML. Interrater reliability: the kappa statistic. Biochem Med 2012;22:276-82.

22 Leber AW, Eichinger W, Rieber J, et al. MSCT guided sizing of the Edwards Sapien XT TAVI device: impact of different degrees of oversizing on clinical outcome. Int J Cardiol 2013;168:2658-64.

23 Binder RK, Rodés-Cabau J, Wood DA, et al. Transcatheter aortic valve replacement with the SAPIEN 3: a new balloon-expandable transcatheter heart valve. JACC Cardiovasc Interv 2013;6:293-300.

24 Abdel-Wahab M, Zahn R, Horack M, et al. Aortic regurgitation after transcatheter aortic valve implantation: incidence and early outcome. results from the German transcatheter aortic valve interventions registry. Heart 2011;97:899-906.

25 Giustino G, Van der Boon RMA, Molina-Martin de Nicolas J, et al Impact of permanent pacemaker on mortality after transcatheter aortic valve implantation: the pragmatic (pooled Rotterdam-MilanToulouse in collaboration) pacemaker substudy. Eurolntervention 2016;12:1185-93.

26 Engborg J, Riechel-Sarup C, Gerke O, et al. Effect of permanent pacemaker on mortality after transcatheter aortic valve replacement. Scand Cardiovasc J 2017;51:40-6.

27 Berdajs D. Aortic root rupture: implications of catheter-guided aortic valve replacement. Curr Opin Cardiol 2013;28:632-8.

28 Leow KS, Wu YW, Tan CH. Renal-related adverse effects of intravenous contrast media in computed tomography. Singapore Med J 2015;56:186-93.

29 Kasel AM, Cassese S, Bleiziffer S, et al. Standardized imaging for aortic annular sizing: implications for transcatheter valve selection. JACC Cardiovasc Imaging 2013;6:249-62.

30 Ruel M, Dickie S, Chow BJW, et al. Interventional valve surgery: building a team and working together. Semin Thorac Cardiovasc Surg 2010;22:145-9.

31 Vahl TP, Kodali SK. Valvular disease: role of cardiac surgery support during contemporary TAVI. Nat Rev Cardiol 2016;13:448-50. 


\section{Correction: Utility of conventional aortic root shot angiography for SAPIEN 3 prosthesis sizing in TAVI: feasibility and inter-reader variability}

Gansera L, Ulm B, Bramlage P, et al. Utility of conventional aortic root shot angiography for SAPIEN 3 prosthesis sizing in TAVI: feasibility and inter-reader variability Open Heart 2019;6:e01201. doi: 10.1136/openhrt-2019-001201.

This article was previously published with incorrect affiliation. The correct affiliations are:

Laura Gansera ${ }^{1}$, Bernhard Ulm², Peter Bramlage ${ }^{3}$, Stephan Krapf $^{4}$, Frank Oertel ${ }^{4}$, Tobias Mueller-Honold ${ }^{1}$, Wolfgang von Scheidt ${ }^{1}$, Christian Thilo $^{1}$

1. Department of Cardiology, Universitätsklinikum Augsburg, Herzzentrum AugsburgSchwaben, Augsburg, Germany

2. USBBU, Unabhängige statistische Beratung, Munich, Germany

3. Institute for Pharmacology und Preventive Medicine, Cloppenburg, Germany

4. Department of Cardiac and Thoracic Surgery, Universitätsklinikum Augsburg, Herzzentrum Augsburg-Schwaben, Augsburg, Germany

Open access This is an open access article distributed in accordance with the Creative Commons Attribution Non Commercial (CC BY-NC 4.0) license, which permits others to distribute, remix, adapt, build upon this work non-commercially, and license their derivative works on different terms, provided the original work is properly cited, appropriate credit is given, any changes made indicated, and the use is non-commercial. See: http://creativecommons.org/licenses/by-nc/4.0/.

(C) Author(s) (or their employer(s)) 2020. Re-use permitted under CC BY-NC. No commercial re-use. See rights and permissions. Published by BMJ.

Open Heart 2020;7:e01201corr1. doi:10.1136/openhrt-2019-001201corr1

Check for updates 